\title{
ENTREVISTA AL DOCTOR JUAN ANTONIO GARCíA AMADO'
}

\section{ABRIL USCANGA BARRADAS}

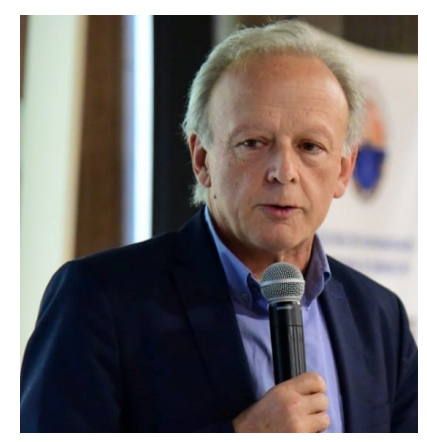

Juan Antonio García Amado es Licenciado y Doctor en Derecho por la Universidad de Oviedo. Catedrático de Filosofía del Derecho de la Universidad de León desde 1994. Recibió el Premio de Investigación en Ciencias Jurídicas y Sociales con ocasión del XXV aniversario de la Universidad de León. Posee la Orden del Congreso de Colombia en el Grado de Cruz de Caballero. Doctor honoris causa por varias universidades latinoamericanas. Miembro del comité editorial o el comité científico de revistas como Rechtstheorie, Doxa, Droit et Société, Derechos y libertades y numerosas publicaciones jurídicas y filosóficas de América Latina. Autor de más de dos centeneras de artículos en libros colectivos y revistas españolas y extranjeras, así como artículos traducidos al portugués, el francés y el alemán. Ha publicado sobre temas de Filosofía y Teoría del Derecho, Filosofía política, Derecho penal, Derecho constitucional, Derecho civil, Derecho administrativo, Derecho laboral, Derecho y cine, Derecho y literatura, etc.

${ }^{1}$ Este documento constituye una transcripción de la entrevista realizada. Se ha revisado sin alterar el estilo coloquial propio de una conversación, considerando que esta característica enriquecería el texto que se presenta al lector. La entrevista fue realizada con la colaboración de Javier Díez García y Yuriria Maryem Domínguez Juárez. 
Entre sus libros de encuentran: Teorías de la tópica jurídica (Civitas, 1988 y Palestra Editores, 2019); Hans Kelsen y la norma fundamental (Marcial Pons, 1996); La filosofia del Derecho de Habermas y Luhman (Universidad Externado de Colombia, 1997) Escritos de Filosofia del Derecho (1999); Ensayos de filosofia jurídica (Temis, 2003); La Lista de Schindler. Abismos que el Derecho dificilmente alcanza (Tirant lo Blanch, 2003); Delito politico (2007); Un debate sobre ponderación (con Manuel Atienza, Palestra, 2012); El Derecho y sus circunstancias (Universidad Externado de Colombia, 2010); Iusmoralismo(s). Dworkin, Alexy, Nino (Cevallos Editora Jurídica, 2015); Teoría de la decisión judicial. Subsunción, argumentación, ponderación (Ediciones Nueva Jurídica, 2016); Filosofia política para juristas. Doctrinas, debates y cuestiones prácticas (Ediciones Doctrina y Ley, 2017), Ponderación judicial. Estudios críticos (Zela, 2019), Razonamiento jurídico y argumentación (Eolas, 2020, segunda edición ampliada; Zela, 2019), entre otros.

Ha editado o coordinado libros colectivos como El Derecho en la teoría social. Diálogo con catorce propuestas actuales (Dykinson, 2001); Torturas en el cine (editor junto con Manuel Paredes Castañón, Tirant lo Blanch, 2005); Filosofía del Derecho penal (editor junto con Miguel Díaz y García Conlledo, Universidad Externado de Colombia, 2006); Prueba y razonamiento probatorio en Derecho. Un debate sobre abducción (con Pablo Bonorino, Editorial Comares, 2014); La responsabilidad civil por daños en las relaciones familiares (Bosch, 2017); Conflictos de derechos. Problemas teóricos y supuestos prácticos (Tirant lo Blanch, 2019), etc.

Redacta el blog Dura Lex (www.garciamado.blogspot.com), de temática jurídica, política y social y colabora habitualmente con el blog jurídico almacendederecho.org.

Director del Máster Online en Argumentación Jurídica impartido por convenio entre la Universidad de León y Tirant Formación.

\section{ENTREVISTA AL DOctor JuAn ANTONio GARcía Amado}

Dra. Abril Uscanga Barradas: Muchísimas gracias, doctor Juan Antonio García Amado, es un gran placer estar aquí con usted y quiero agradecerle que haya aceptado que le realicemos esta entrevista. 
Dr. Juan Antonio García Amado: Un gusto para mí también, querida Abril, y encantado de tenerte de nuevo en León, en esta universidad que sabes es tu casa.

AUB: Muchísimas gracias de nuevo. Quisiera comenzar hablando un poco acerca de su vida académica, y en particular remitirme a su vida como estudiante. Me gustaría preguntarle qué lo impulsó a estudiar Derecho.

JAGA: Tengo para eso una historia que puede sonar a leyenda, pero es estrictamente real todo lo que voy a decir. Yo era un joven campesino que estudiaba en la ciudad, le había tomado afición a la Filosofía y mi deseo inicial hubiera sido estudiar Filosofía. Ese deseo se frustró porque en aquel tiempo, estamos hablando del año 1974, no existía la carrera de filosofía en la Universidad de Oviedo, en mi región, y en casa no teníamos dinero para que yo pudiera irme a estudiar fuera. Así que no sabía muy bien qué hacer. Un día, ese año anterior al ingreso a la universidad, me fui al cine con un compañero de mi colegio, que se llamaba Andrés Meré Antón, recuerdo que fuimos a ver la película fesucristo Superstar. En un descanso que tenía la película nos pusimos a hablar y él me contó que pensaba estudiar Derecho. A mí eso me quedó sonando como algo que nunca me había planteado, él era un grandísimo estudiante. Pasó el fin de semana, y el lunes, al llegar a mi colegio, encontré un gran revuelo en el patio y personas llorando. Cuando pregunté qué había pasado, me dijeron que ese fin de semana se había suicidado Andrés Meré. Se había suicidado ese muchacho, y a mí me había quedado en la cabeza la idea de estudiar Derecho y, por las circunstancias que sean, me ratifiqué en ella, pero muchas veces he pensado que yo ocupé su lugar, acabé haciendo, por influencia suya, lo que él iba a hacer. Entonces la vida me favoreció al no permitirme estudiar Filosofía, porque más adelante, al terminar de estudiar la carrera de Derecho, descubrí que es apasionante, y la Filosofía que hacen la mayor parte de los filósofos actuales no me interesa nada, porque es especulativa. 
AUB: Doctor, con relación a lo anterior, ¿dónde estudió? Es decir, ahora usted es catedrático en la Universidad de León, pero no fue estudiante de esta universidad.

JAGA: No, yo estudié en la universidad de Oviedo, una de las universidades antiguas y tradicionales de España. Está en Asturias, que es la región de la que yo provengo. En esta Universidad de León obtuve mi catedra en noviembre de 1994. Estudié en aquella universidad de Oviedo, que, como digo, era una Universidad antigua, tengo muy buen recuerdo de aquellos tiempos, pero la carrera en realidad no la disfruté, sino que la padecí; creo que no se enseñaba el Derecho de un modo muy distinto a como lo seguimos enseñando a día de hoy. Pese a tantos cambios cosméticos en métodos y planes de estudio, todo es mentira, no se puede cambiar una cultura profesoral, una cultura académica, por decreto. El Derecho, en nuestra cultura, en España y también en Latinoamérica, es una rama de la Metafísica, que se enseña como se enseña Teología. Se obliga a memorizar conceptos cuyo sentido ni el propio profesor entiende, todo el rato se anda en definiciones y en memorizar naturalezas jurídicas y cosas inverosímiles; es decir, tenemos una tradición doctrinal que aleja el derecho de la práctica y lo convierte en una ciencia esotérica, en una cábala, en una disciplina que cultivan los sacerdotes, un templo que en realidad está vacío. Ahí está la contradicción, yo tengo un buen recuerdo de la carrera, de la época, también de la bonhomía y amabilidad de muchos profesores, aunque otros eran unos torpes y de todo tiene que haber en la viña del Señor; tengo un buen recuerdo de la carrera, pero, como antes decía, descubrí el interés y la belleza del Derecho cuando me fui liberando de todo ese artefacto postizo de conceptos y categorías abstrusas.

AUB: ¿Recuerda quiénes fueron esos profesores o juristas que más influyeron en su pensamiento?

JAGA: Hubo un profesor que fue absolutamente decisivo en mi vida. Por una casualidad afortunada, cuando llegué al primer curso de Derecho tuve una primera clase de una asignatura que se 
llamaba Derecho Natural. Llegué a dicha clase y me encontré ahí a un señor que decía cosas muy interesantes y con un tono muy retador para aquellos tiempos. Recordemos que cuando comencé la carrera era octubre de 1975 y aún estaba vivo Franco, el dictador que, por fortuna para todos, murió al mes siguiente, el veinte de noviembre. Me fascinó aquel profesor, lo que decía y su estilo. En ese mismo momento me dije: "Ya sé qué quiero ser". El profesor se llama Elías Díaz. En aquel tiempo yo era un muchacho muy tímido y no me acerqué a él en ningún instante, no le dije nada, pero me motivó mucho. Por desgracia para mí, al año siguiente se marchó de la Universidad de Oviedo, pero no olvidé su estilo e influencia. Fue muchos años más tarde, cuando yo ya era catedrático también, cuando le dije: "Yo estoy aquí por ti, por lo que aquello significó". Primero se sorprendió, después, naturalmente, quedó muy feliz, eso es lo que todos los profesores soñamos, que un día un alumno despistado nos diga "Oiga, qué bueno ha sido usted para mí". Él, sin saberlo entonces, fue decisivo en mi vida.

En cuanto a otros profesores, dentro de aquel viejo estilo académico tuve a algunos que explicaban bien, que cultivaban con cierto gusto su materia, y padecí otros que era evidente que se dedicaban a la cátedra porque no servían para cuidar ovejas; pero el balance, como digo, no fue malo. Cuando terminé mi carrera había un profesor de Filosofía del Derecho que se llamaba Luis Martínez Roldán, que fue quien me abrió las puertas para ingresar como joven profesor, y por aquellos años hubo un decano que se llamaba José María Muñoz-Planas, que de igual manera me favoreció cuando obtuve una beca para irme a Alemania a comenzar mi tesis doctoral y me dio todo su apoyo para que no perdiera mi vinculación con la Universidad de Oviedo. Eran buena gente, eran otros tiempos en muchísimos sentidos. Cuando recuerdo todo esto me siento viejo, porque en aquel entonces los profesores, buenos o malos, no gastaban partes preciosas de su tiempo haciendo o diseñando metodologías, escribiendo memorias, soportando cursos de renovación 
pedagógica... tantas cosas absurdas y radicalmente improductivas que en nuestros días agotan al académico y lo hacen sentirse un pelele sin razón de ser.

AUB: Gracias por compartirnos su experiencia. En este mismo sentido, doctor Juan Antonio, quiero decirle que me ha llamado mucho la atención todo lo que ha mencionado, y me voy a permitir preguntarle en relación a uno de los cambios más importantes en la historia reciente de España. Me refiero al final de la dictadura. Lo traigo a colación porque conozco y he seguido parte de lo que usted escribe continuamente en su blog, del que creo nadie debe perderse la lectura. ¿Cuál fue realmente este cambio al final de la dictadura que tal vez no todos tienen la posibilidad de recordar o de haber vivido? ¿Cómo es la transición que se realiza de una dictadura hacia una democracia española y cuáles son los riesgos actuales?

JAGA: Habría para hablar horas y horas, pero trataré de dar cuatro pinceladas sobre lo que pienso al respecto. El paso de la dictadura a la transición democrática fue el paso de la oscuridad a la luz. Soy completamente sincero si digo que todavía me tocó en el colegio, durante mi adolescencia, que los profesores y algunos curas nos explicaran aquello de que si uno se masturbaba se le disolvía la medula espinal y se quedaba sin poder caminar, se le derretían los huesos y todo ese tipo de cosas. Recuerdo una adolescencia en la que quien tenía una fotografía con los senos de una mujer poseía un tesoro, y en los lados más apartados del patio nos enseñábamos ese tipo de imágenes unos a otros con fruición. Aquello era gris, sórdido, autoritario. Nos llegó la luz de muchas maneras, nos llegó la libertad pacíficamente, las distintas fuerzas políticas se pusieron de acuerdo para hacer una Constitución democrática con un alto contenido social. También en la universidad se respiró la libertad, en concreto en nuestra disciplina, en la Filosofía del Derecho, comenzó a florecer toda una generación de muy buenos profesores, en la estela de gente, como, por ejemplo, Elías Díaz, Gregorio Peces-Barba o Antonio Enrique Pérez-Luño. Fueron apareciendo filósofos del 
Derecho que renovaron la disciplina por completo. Pienso también en una generación más adelante, en lo que significaron personas como Manuel Atienza Rodríguez, Luis Prieto Sanchís, Rafael Hernández Marín, Francisco Laporta, Alfonso Ruíz Miguel, entre algunos otros que merecerían igualmente ser nombrados.

Todo eso también se fue agotando en todos los órdenes, la universidad se burocratizó muchísimo, no conseguimos que funcionaran buenos sistemas de selección del profesorado, la Filosofía del Derecho se volvió mucho más fácil o facilista, superficial. En mi opinión, hicieron mucho daño algunos temas, como el de los derechos humanos, toda vez que, aunque son un asunto realmente crucial en nuestra vida, se dedicaron los menos dotados para la Filosofía del Derecho a cultivar su supuesta teoría y, simplemente terminaron diciendo cosas que ya sabía mi abuela y que no justificaban una monografía y semejante repetición de tópicos sin reflexión ninguna. Todos esos repetidores de simplezas como el que dice que son muy importantes la libertad y la igualdad y que hace falta encontrar un equilibro entre las dos, o trivialidades semejantes, han hecho mucho daño porque se ha dejado de cultivar la teoría del derecho o la filosofía política en serio y hablamos nada más que de globalización, de derechos humanos en ese sentido inane, de políticas de género para dummies, etc. Y, en mi opinión, la sociedad española también está pagando en este momento las consecuencias de un Estado del bienestar mal digerido, de una libertad que ya no se valora. Quizá hay demasiados ciudadanos españoles que ahora votan con injustificado resentimiento. Y en nuestro gremio, en la Universidad, entre supuestos intelectuales aparece un problema freudiano, hay mucha gente votando por el mal porque votan contra su "papá"; es decir, están tristes porque saben que a ellos les ha venido todo muy fácil gracias a lo injusta que es la sociedad, y entonces no renuncian a su sueldo, pero "matan" a su padre votando a partidos que prometen acabar con todo lo que hay. Hemos llegado a un insuperable nivel de incongruencia y a una estúpida apoteosis del populismo. 
AUB: En ese mismo sentido, ahora que ha mencionado a estos juristas actuales, me gustaría mencionar a uno en particular, de quien tengo la curiosidad por saber los vínculos que han tenido en el pasado. Me refiero a Manuel Atienza, quien tengo entendido que también cursó sus estudios en la Universidad de Oviedo.

JAGA: Si, Manuel Atienza es asturiano como yo, él es de un pueblo a las afueras de Oviedo que se llama Trubia, en donde nació porque su padre trabajaba como médico en la fábrica de armas que había en ese pueblo. Manuel Atienza estudió en Oviedo y comenzó joven como profesor en aquella Universidad, justamente cuando estaba allí Elías Díaz. Cuando yo iniciaba mi carrera, en ese primer curso tan importante para mí, recuerdo que un día apareció Manuel Atienza en el aula a sustituir al maestro Elías Díaz, y yo me quedé pensando: ¿Quién será ese tipo tan peculiar? Luego acabamos siendo colegas y, sobre todo, terminamos por ser buenos amigos. Manuel Atienza ha hecho un periplo muy largo: se fue a Valencia con Elías Díaz, luego a Madrid y Mallorca, y terminó en Alicante. Más sus estancias fuera de España. Él ha sido y es una persona muy importante en la Filosofía del Derecho española, por su gran capacidad de trabajo, su talento para formar equipos y su capacidad también para extender por tierra, mar y aire ideas iusfilosóficas muy importantes. Eso al margen de que yo discrepe con algunas de esas ideas, lo cual es secundario a la hora de apreciar los enormes méritos de Manolo.

AUB: Muchas gracias por esta aclaración. Pasando de la vida de estudiante a la vida de académico, quisiera preguntarle cuántos años lleva de profesión académica.

JAGA: Yo tengo ahora sesenta y uno, llevo en esto desde los veintidós o veintitrés años. Salen casi cuarenta años.

AUB: ¿Podría describirnos cómo es la relación entre profesor y estudiante en las universidades españolas en la actualidad?

JAGA: Hay muchos profesores españoles que están quemados, por decirlo en la terminología que solemos utilizar aquí. Eso se debe 
a varias razones, y una de ellas es la burocracia; otra es el modo tan extraño - especialmente para los que tenemos cierta edad- con el que se valora el rendimiento académico, y, otro motivo de que muchos buenos profesores se cansen o se aburran es porque el estudiante español actual es un estudiante muy pasivo, un estudiante muy poco motivado, con muy pocos estímulos, apenas adiestrado en el esfuerzo y con un bagaje cultural y un interés intelectual verdaderamente escasos. Por poner algún ejemplo sin extenderme, en los últimos años a los que comenzaban mi asignatura de Teoría del Derecho, en el primer curso de Derecho, les hice un pequeño test de conocimientos elementales y les pregunté cosas como de qué año es la vigente Constitución española. Algo menos del cincuenta por ciento no lo sabía. Les pregunté en qué año terminó la segunda guerra mundial, y el setenta por ciento lo ignoraba. Les pregunté cuáles son las provincias de la Comunidad Autónoma de Andalucía y el treinta por ciento no fue capaz de ponerlas todas. Otra pregunta fue por el director de una película que se acababa de estrenar a bombo y platillo y con gran presencia en los noticiarios. La respuesta correcta era Pedro Almodóvar, pero, de cien, solo dos acertaron. No son de este mundo, son seres fugaces, etéreos, bien alimentados y evanescentes. Son muy buenas personas, pero están completamente alienados.

Desde mis recuerdos, el estudiante medio era, en cierto sentido moral, más peligroso hace treinta años, más pícaro, capaz de hacer cualquier trampa, utilizaba su inteligencia para cualquier cosa y, a veces esa cualquier cosa podría incluir una cierta maldad. El estudiante de hoy es lo más parecido a una vaca. Yo adoro a las vacas, por lo que no es despectiva la comparación. A una vaca uno la pone ante el pesebre y la vaca no se preocupa mucho por si ha estallado la tercera guerra mundial o no; y el estudiante tampoco. Eso desmotiva al profesor y hace presagiar cosas temibles. El mundo va mal porque en otro tiempo tal vez a las personas las crisis graves no las pillaban tan desprevenidas como creo que sí van a pillar despreve- 
nidos a estos jovencitos de hoy. Si una grave crisis llega, estos jóvenes no están moral ni psicológicamente preparados para soportar hambre ni necesidad de trabajar y, además, consideran que es poco menos que de derecho natural la obligación que tiene alguien en el mundo, ya sea Dios la familia o el Estado, de alimentarlos y de darles un teléfono móvil de última generación. No es culpa suya, ya que es el sistema social el que ha evolucionado así.

Los españoles nos hicimos ricos en poco tiempo y considero que solo se asimila la riqueza o la pobreza cuando son el resultado de un lento transcurrir de generaciones. Hay estudios que muestran que si a alguien le toca un gran premio de la lotería es muy probable que al cabo de unos cinco años esté peor y más arruinado que antes de recibir el premio, porque no están los individuos preparados para administrar su riqueza súbita. En mi opinión, eso mismo explica la evolución de la sociedad española, no estábamos listos para la libertad y acabamos odiándola, no estábamos preparados para el sexo libre y acabamos pensando que todo es violación, no estábamos preparados para comer caliente todos los días y creemos que es maná que nos ha de caer del cielo. Esos estudiantes nuestros de hoy en día son buenas personas que no tienen la culpa de que la generación anterior esté destruyendo las conquistas de esa misma generación o de la anterior, y no están entrenados estos muchachos y muchachas para afrontar cualquier crisis o necesidad que sobrevenga.

AUB: Muy interesante. Ahora quisiera adentrarme un poco en algunas cuestiones del ámbito teórico. Me gustaría preguntarle, quizá presionándolo un poco, cómo se considera o cómo se califica usted mismo dentro de la teoría jurídica.

JAGA: Soy alguien que gusta mucho del Derecho, casi me atrevería a decir que vivo enamorado del Derecho y de todo lo que rodea el Derecho y organiza la vida social. Dentro de la teoría del Derecho, me adscribo al positivismo jurídico, pero soy un iuspositivista por razones morales y estimo que no hay ninguna contradicción en eso. Creo que uno de los mayores logros civilizatorios de nuestra 
cultura occidental ha sido el de que sociedades en las cuales hay personas plurales, personas distintas, personas con diversas concepciones del bien, de lo bueno y de la vida buena, tengan un Derecho en común que pone las reglas básicas de convivencia para que podemos interactuar en la libertad y en la diversidad. Nos ponemos de acuerdo sobre ciertas reglas mínimas que han de tener el respaldo coactivo del Derecho; por ejemplo, nos ponemos de acuerdo sobre cómo se hace un contrato o cuándo es válido un contrato o simplemente cuál es la fuerza de un contrato, o acordamos qué comportamientos merecen ser castigados como delitos. A eso de ponerse de acuerdo entre diferentes, cada uno de los cuales puede expresar libremente sus ideas, es a lo que se llama democracia. Así que yo me considero positivista jurídico por liberal en el sentido político y por socialdemócrata en el sentido social; por demócrata, en suma.

Valoro el Derecho, y, al valorar el Derecho, considero también que hay que rescatar un espacio adecuado para la dogmática jurídica, la cual me parece que en estos tiempos está en crisis. Hay que volver a hacer buena teoría penal, buena teoría del Derecho administrativo, buena teoría del Derecho privado, buena teoría constitucional, porque hay hoy en día una especie de curiosa y paradójica eclosión de una filosofía del derecho metafísica y casi iusnaturalista, que lleva a tantos jóvenes cultivadores de la ciencia jurídica a pensar que no importa nada lo que de científico o analítico pueda haber en el estudio del Derecho y que solo cuenta hablar de los derechos humanos, del género y de cosas de ese estilo, que son muy importantes, pero de las que muchas veces hablamos sin la autoridad científica que esos temas requieren, a la vez que abandonamos lo que en realidad puede ser nuestra aportación, que tiene que ser una aportación técnica.

A mí me gusta decir que los juristas tenemos mucho en común con los ingenieros, los ingenieros tienen que saber diseñar puentes que no se caigan, y nosotros tenemos que ser capaces de dibujar y diseñar sistemas normativos que permitan la adecuada protección 
de aquellos bienes que nos parecen más valiosos. Eso se hace estudiando buena dogmática, forjando conceptos sólidos, construyendo buena teoría del derecho y no recitando esos mantras de "todo el mundo tiene que ser bueno" "cuidemos a nuestros viejos" "amemos a nuestros niños", "practiquemos un sexo ordenado" ... La filosofía del derecho actual se reduce a esos cuatro mantras, y si le agregamos tres más de ese estilo, acabaremos nuevamente diciendo lo de la médula espinal que me contaban a mí de jovencito. Es una pena y una pérdida que estemos dejando de prestar nuestro servicio como juristas, para convertirnos en algo bien parecido a obispos. La diferencia es que el obispo de antes llevaba sotana y comía mucho, mientras que el "obispo iusfilósofo" va sin sotana y sin corbata y con pañuelo palestino y se está haciendo vegano, pero en lo demás es el mismo espíritu religioso. Lamentable.

AUB: ¿Cómo podemos definir el positivismo jurídico, dejando de lado sin duda las caricaturas que se han empeñado en hacer muchos principialistas o postpositivistas?

JAGA: La seña de identidad del positivismo jurídico es lo que se conoce como tesis de la separación conceptual entre Derecho y moral. Esto significa que a la hora de identificar si una norma es jurídica o no lo es (porque puede ser una norma de otro tipo, puede ser una norma de cortesía, moral o religiosa, propia de una determinada iglesia o credo), no se mira su compatibilidad con la religión o la moral, sino que se reconoce autónomamente el Derecho como realidad que se constituye a partir de las condiciones que los propios sistemas jurídicos ponen para la validez de las normas que pertenecen al respectivo sistema. Dicho más claramente, cuando a alguien se le pregunta si una norma que hay en el Código Penal es Derecho o no lo es, contesta que sí, por el hecho de que esa norma está en el Código Penal, y separa ese juicio, ese reconocimiento, de su opinión sobre la justicia de esa norma o de su idea de si esa norma ampara un pecado o protege una virtud, y al final resulta que hay un acuerdo social en que lo que está en ciertos documentos, en ciertos cuerpos 
jurídicos, es Derecho, y en que lo es por el modo en que han sido esas normas creadas y producidas. Son los propios sistemas jurídicos los que regulan la producción de sus propias normas.

Todo esto tan complejo a mí me gusta explicarlo con un ejemplo que continuamente menciono y es el siguiente. Nosotros, todos, somos capaces de separar, de diferenciar conceptualmente el sexo y el amor, a pesar de que muchos compartamos la idea de que lo ideal es que se den juntos, porque es estupendo cuando el amor va acompañado de sexo y qué bueno el sexo cuando es con amor y no de otra manera. Al margen de ese ideal, usted es capaz de reconocer que el sexo sin amor también es sexo y que el amor sin sexo también es amor, por lo que usted está separando conceptualmente cosas que muchas veces se dan unidas y que nos gusta que aparezcan unidas. Pues eso es lo que dice el positivista, que hay normas jurídicas injustas y que hay normas morales de contenido antijurídico y que ni las unas ni las otras dejan de ser lo que son por causa de esa contradicción con otro sistema normativo. La compatibilidad con la moral no es condición de validez de la norma jurídica y la compatibilidad de las normas morales con el Derecho no es condición de validez de las normas morales; es decir, la norma moral que rige para un comportamiento vale o no vale como norma moral con independencia de que sea compatible o no con lo que el Derecho diga de ese mismo asunto.

La tesis iuspositivista de la separación conceptual entre Derecho y moral no niega de ningún modo que haya materialmente conexiones entre Derecho y moral, porque naturalmente que sí hay empíricamente un montón de conexiones entre Derecho y moral, Derecho y economía, Derecho y política, Derecho y poder, etc., pero lo que el positivismo señala es que cada cosa es lo que es, porque socialmente reconocemos cada cosa como distinta de las otras. Socialmente, sabemos diferenciar los Mandamientos de la Ley de Dios y las normas del Código Penal como normas pertenecientes a sistemas distintos y que obligan de manera diferente. El iusnatura- 
lista opinaría que no, para él el Derecho, para ser verdadero Derecho, tiene que estar de acuerdo con los Mandamientos de la Ley de Dios, pero el positivista insiste en que cada cosa es lo que es.

Hagamos un acto de humildad para asumir que es posible que algo sea Derecho aunque a mi conciencia le repugne. Eso es lo que un iusmoralista no soporta, ya que se pregunta: ¿cómo voy a estar yo en radical desacuerdo con una norma y va a seguir siendo Derecho esa norma? El iusmoralista es una persona con un ego grande o con aspiraciones de vida eterna. Por su parte, el iuspositivista trata de vivir una buena vida en conjunto o en sintonía con todos los demás, incluidos los iusmoralistas, porque piensa que los iusmoralistas tienen el mismo derecho que él a decir lo que piensan, y por eso el Derecho no puede ser de cada uno y según lo que cada uno prefiera, sino que tiene que ser común, ha de ser para todos. Y en un Estado de Derecho democrático hay procedimientos para que el Derecho sea de todos, y no solo de los que se creen más listos o más cultivados.

AUB: No hay consenso u opinión unívoca en relación a la definición misma de algo tan básico como el Derecho. ¿Podríamos considerar que en realidad el Derecho podría asemejarse, y con ello la Filosofía del Derecho, a la ciencia?

JAGA: Siempre se repite aquello, que ya dijo Kant, de que no somos capaces de ponernos de acuerdo en una definición del Derecho o en un concepto de Derecho. Pero socialmente el Derecho está perfectamente identificado, en el sentido de que cualquiera está al corriente de que cuando hay un semáforo en rojo, para saber si debe parar o no tiene que informarse sobre lo que dice una norma jurídica y no tiene que preguntarle al cura, por ejemplo, o al profesor de ética; tiene que preguntarle a la norma jurídica porque todos identificamos la norma jurídica. Cuando los iusmoralistas les dan clases a sus estudiantes de Derecho en las facultades de Derecho, les enseñan el Código Civil, el Código Penal, la Constitución, etc., y luego les dicen que seguramente hay otras cosas que alguna vez 
derrotan a tales normas jurídicas. Se reservan así un as en la manga para hacer de su capa un sayo cuando una norma jurídica no les agrada por razones ideológicas o religiosas, por ejemplo.

Hay un acuerdo básico sobre qué es el Derecho, dónde está y en qué consiste en cada sociedad y en cada momento. El Derecho sí está identificado. Cuestión distinta es que hacer teorías de las normas y teorías de los sistemas normativos tiene dificultades intrínsecas, pero son dos asuntos diferentes. Creo que no es tan difícil tener o hacer un concepto de Derecho que refleje el modo en que la sociedad vive el Derecho, siente el Derecho e identifica el Derecho. Pero parece imposible que los iusfilósofos nos pongamos de acuerdo en el concepto, porque, en primer lugar, nosotros tenemos que enredar la realidad para que parezca que hay mayor justificación para nuestro oficio. A eso se añade que los profesores de Derecho, en general, y los iusfilósofos, en particular, tenemos un ego desmesurado, una soberbia estremecedora, y por eso nos cuesta asumir que el Derecho sea algo tan prosaico que está ahí afuera y que es el mismo para mí y para el conductor del autobús. ¿Cómo va a ser lo mismo para uno y para otro, con todo lo que nosotros hemos estudiado? Ahí se detecta poco menos que un trastorno psíquico del profesor. El fontanero, el conductor del bus, el panadero o el arquitecto saben perfectamente donde está el Derecho y lo que es, aunque no sepan definirlo, mientras que el iusfilósofo intenta definirlo y acaba olvidándose de dónde está y de lo que es; salvo cuando trata con Hacienda, pues entonces hasta el más feroz iusnaturalista se vuelve positivista y con un dedo autoritario señala al inspector de Hacienda lo que dice la norma, siempre que la norma a él lo favorezca. Todos tenemos muy claro qué es el Derecho y donde está, aunque algunos disimulen cuando les conviene.

AUB: Sabemos que una parte sustancial de su labor académica está relacionada con la argumentación jurídica, incluso conocemos que sobre ese tema ha dictado abundantes cursos en Latinoamérica. Los latinoamericanos estamos muy interesados en saber las dife- 
rencias entre reglas y principios y entiendo que usted ha llegado a considerar que los conflictos podrían ser aparentes y hasta pone en duda la existencia de los principios. ¿Podría comentarnos un poco acerca de estos asuntos y, solventarnos la duda de la existencia real de los principios?

JAGA: Es una pregunta complicada. Yo creo en el valor de esa parte de la teoría del derecho tan actual y tan de moda que se llama teoría de argumentación jurídica. Pero no hay una sola teoría de la argumentación jurídica, sino que hay distintas orientaciones. Hay cultivadores de la teoría de argumentación jurídica más afectos al positivismo jurídico, como es mi caso, y hay otros, como el propio Alexy o como Manuel Atienza, que establecen una unión muy estrecha entre teoría de argumentación jurídica y iusmoralismo. Yo creo que existe un acuerdo de mínimos en que el Derecho tiene un fin práctico, en que lo que da sentido al Derecho es la práctica y en que esa práctica tiene una fuerte dimensión argumentativa. Argumentar es dar razones, un argumento es una razón que sostiene una tesis del tipo que sea. Eso es la argumentación, dar razones.

Lo que sucede es que en Latinoamérica este asunto de la argumentación jurídica se está viviendo de un modo especial, y yo diría que por varios motivos. Medio en serio y medio en broma, pero más en serio que en broma, me permito decir, en primer lugar, que el hermano latinoamericano es muy de buscar la piedra filosofal; es decir, andamos buscando algo que convierta el agua en oro y, esto de la argumentación jurídica se ha visto como la solución de todos los problemas de Derecho. Se ha creído que si se sabe de argumentación jurídica ya no hace falta saber Derecho penal o Derecho civil, pongamos por caso, porque argumentando lo resolvemos todo. Se nos ha querido convencer de que en realidad practicar bien el Derecho no es andar haciendo racionamientos muy complicados sobre la relación entre una norma y un caso, sino que se trata de ponderar principios. También se nos ha contado que la verdadera naturaleza del Derecho está en algo metafísico que late bajo las 
constituciones y que se llama principios, y que dichos principios tienen una especie de naturaleza a medias moral y a medias jurídica. La gente termina creyendo que si sabe argumentar con principios apenas necesitará estudiar más. De ahí viene gran parte de la crisis de la dogmática jurídica a la que me he referido antes.

Hubo antes en Latinoamérica un llamado pensamiento crítico del Derecho que nos dijo que el Derecho es un instrumento de dominación muy horrible y cuanto más estudie usted Derecho penal, por ejemplo, más cómplice se hace usted de lo más abominable de tal sistema de dominación inicua. Eso restó legitimidad a cualquier voluntad de construir sistemas jurídicos basados en algo parecido a una ciencia jurídica, una ingeniería jurídica o una ingeniería social. Y detrás, ahora, vinieron los curas sin sotana a decir que en realidad practicar el Derecho es andar sometiendo a escrutinio moral cada caso a resolver, porque siempre va a haber un principio constitucional expreso o implícito que al operador jurídico se le va a aparecer y le va a iluminar con ese efecto de irradiación que tienen los principios. Puro esoterismo. De ese modo, el Derecho se convierte en una rama de la Metafísica y en materia que cultivan ciertos supremos sacerdotes y, se deja de estudiar Derecho de verdad, para dedicarse a todas estas extrañas religiosidades.

La teoría de la argumentación jurídica es necesaria, es una rama de la Teoría del Derecho sumamente interesante y que tiene que ver con la justificación intersubjetiva de la decisión jurídica, con la interpretación y aplicación del Derecho. Pero que va paso a paso cayendo en manos de cultivadores que no tienen tanto interés en la aplicación de las normas específicas del sistema jurídico como en la moralización sesgada o interesada de las constituciones y de la vida social. Ahora los viejos iusnaturalistas andan casi todos disfrazados de alexianos y echando agua bendita con su ponderómetro.

El principalísimo de estilo dworkiniano y alexiano que hoy domina, en especial en Iberoamérica, es sumamente dañino para nuestros derechos. Con el esquema de Dworkin o Alexy, todas las normas, 
digan lo que digan, son derrotables. Según Alexy, todas las normas de un sistema jurídico son reglas o principios, y resulta que tanto se pondera un principio contra otro principio, como un principio con una regla. Siempre hay un principio expreso o implícito que puede derrotar a cualquier norma del sistema, sea otro principio u una regla, lo que significa que yo no tengo ningún derecho seguro, ni siquiera en su núcleo o contenido esencial. Por ejemplo, la Constitución española dice que la tortura está prohibida, lo cual, traducido a derecho subjetivo, significa que yo, como ciudadano español, tengo derecho a no ser torturado. Pero un principialista diría que mi derecho a no ser torturado rige, sí, pero prima facie o en principio, rige siempre y cuando que en el caso concreto concurra un principio que pese más que la norma que me protege contra la tortura.

Hay una paradoja atroz que yo creo que algún día tendrá que acabar de revelarse y que consiste en que este principalísimo está atacando a la misma línea de flotación del Estado constitucional, democrático y social de derecho, pues todas aquellas conquistas que cobraron la forma jurídica de derechos fundamentales se están disolviendo por obra de una teoría jurídica que, so pretexto de moralizar la práctica del Derecho, en realidad no respeta ningún bien o valor legal o constitucionalmente fijado y lo somete todo al escrutinio puntual de los tribunales caso a caso. Si a esa inseguridad, si al hecho de que todo lo que en la Constitución parece cierto en la práctica se vuelve inseguro porque hay que ponderar caso a caso, le añadimos un elemento más que voy a mencionar, el cóctel es infernal ¿Cuál es ese elemento? Ese elemento es la falta de independencia judicial, de verdadera carrera judicial y de auténtica profesionalidad de los jueces en muchos países de Latinoamérica en los que los magistrados y las magistradas que quieren mantener su puesto y seguir llevando un sueldo a casa tienen que procurar no desagradar en exceso a los poderes establecidos. Ese juez al que le falta independencia y al que a veces le falta también adecuada formación se ve obligado a complacer a los poderes establecidos y 
dominantes en su Estado ¿Y qué va a hacer? Va a ponderar ¿A favor de quién? A favor del poderoso, cuando haya algo en juego que sea bien valioso para los poderosos.

Al pueblo llano, al pueblo humilde, lo único que le protege es la ley férreamente aplicada, y todas las revoluciones se hicieron con el objetivo de traducir a legalidad conquistas sociales básicas. Cuando se ataca la legalidad democráticamente legitimada en nombre de los principios y nos creemos que al hacerlo así estamos siendo progresistas, solo estamos siendo cómplices de la reacción más perversa, estamos siendo reaccionarios, lo sepamos o no. Yo tengo una apuesta con muchos amigos, la apuesta de que a ese principalísimo le quedan apenas diez años en Latinoamérica, porque ya se le están viendo las orejas al lobo, los latinoamericanos ya están mirando qué pasa en Brasil o Colombia y en tantos otros lugares donde de pronto esos jueces tan ponderadores dejan de ponderar del modo que nos gusta a los que nos consideramos progresistas y empiezan a ponderar a favor de Bolsonaro o contra Dilma Rousseff o empiezan a derribar lo que se consideraban conquistas jurisprudenciales poco menos que irreversibles. Es entonces cuando todos esos que alababan a Alexy salen con una linterna a buscar kelsenianos. Esperemos que no sea demasiado tarde y que aun podamos librarnos de la seria amenaza de un autoritarismo adornado de moralina y de un antilegalismo y antiparlamentarismo que siempre acata la voz de su amo, que no es precisamente la voz del pueblo que en la ley ha de expresarse.

AUB: Me ha parecido sumamente clarificador lo que ha comentado, sin duda ha tomado gran relevancia en el debate lo que va a suceder en los próximos años, ya nos ha adelantado que el principalísimo en este juego de péndulo seguramente tendrá la necesidad de un cambio inminente y, ese cambio, por lo que entiendo, considera que será hacia el positivismo jurídico ¿Será que el positivismo jurídico pueda llevarnos a buenos términos? Es decir, la pregunta en particular sería sobre si el debate jurídico se perfila en realidad 
hacia el positivismo jurídico. ¿Podríamos hablar de otra clase de positivismo jurídico? ¿Cuál es su consideración en relación a esto? Algunos teóricos consideraron que el positivismo jurídico nos había conducido a las grandes tragedias de la historia de la humanidad, como el holocausto y el nazismo $\dot{¿}$ Tiene sentido una vuelta al positivismo como salida a esta situación que vivimos?

JAGA: Empiezo por el final. Esa idea tan extendida de que el positivismo jurídico normativista o de estilo kelseniano tiene una especie de responsabilidad moral respecto de la barbarie nazi y del uso espantoso que los nazis hicieron de lo jurídico es una idea difundida por los mismos nazis después de 1945, eso está absolutamente claro y demostrado. Fue la tesis que mantuvieron personas que durante el nazismo habían militado en el partido de Hitler, personas que entre 1933 y 1945 no citaban a Kelsen como Hans Kelsen sino como el judío Kelsen o el "perro judío" Kelsen, personas que repitieron cientos y miles de veces en sus escritos que el positivismo era una doctrina antialemana, liberal, judaica y disolvente. Después de 1945 comenzaron repetir que ellos mismos no se habían opuesto a Hitler porque Kelsen los había convencido de que la ley era la ley y que había que obedecerla y de que la ley engendra no solo la obligación jurídica de obediencia, sino también una obligación moral de obediencia.

En primer lugar, Kelsen nunca dijo eso. En segundo lugar, todos esos individuos nunca habían sido kelsenianos, pero convirtieron a Kelsen en pretexto y cabeza de turco, en chivo expiatori. Esos nazis, para no reconocer su culpa como nazis y porque la mayor parte de ellos nunca dejaron de ser y de sentirse nazis, le echaron la culpa otra vez al judío Kelsen. Esto está históricamente demostrado, sin vuelta de hoja, de modo que el profesor que siga repitiendo en sus clases esa idea de que el positivismo tiene algo de culpa de las atrocidades del nazismo es un ignorante, sea iuspositivista o iusnaturalista, porque la mentira es mentira, la diga Agamenón o la diga su porquero. 
Es muy interesante esa historia porque, precisamente en Alemania y por obra de aquellos constitucionalistas alemanes ultra conservadores, como Dürig o Maunz, se gesta la idea de que la Constitución es un orden objetivo de valores, como dijo Dürig en 1959 y como dijo el propio Tribunal Constitucional Alemán en el caso Lüth en el mismo año. Se insiste en ese momento en que lo que de verdad importa de la Constitución no es el texto, los enunciados o lo que las normas digan, se interprete como se interprete, sino que lo determinante es un trasfondo o cimiento moral, y que cuando el Tribunal Constitucional hace control de constitucionalidad no tiene que mirar si hay contradicción o no entre la ley y la norma constitucional, sino que debe hacer un diagnóstico moral de esa ley, ya que si sale injusta o sale inmoral, entonces es por definición contraria a algún principio moral constitucional.

Esa idea, que es clave en el neoconstitucionalismo actual, es una idea que crean aquellos constitucionalistas ultraconservadores y que habían militado en su gran mayoría en el partido nazi, militantes de carnet y cuota mensual y que habían escrito todas las locuras inimaginables a favor de Hitler y su apestoso régimen. Tengo una pequeña colección de textos de aquel tiempo, textos sobrecogedores por su miseria moral y su bajeza. Después de la Ley Fundamental de Bonn, de 1949, lo que temían aquellos reaccionarios viscerales era la democracia, y por ese temor estaban poseídos durante la década de los cincuenta y los sesenta. Se preguntaban qué iba a pasar en Alemania el día que un partido socialista ganara unas elecciones y pretendiera ejecutar un programa legislativo que facilitara el divorcio, permitiera el aborto, desacralizara la propiedad privada, etc. Entonces se dijeron: tranquilos, porque la Constitución es nuestra desde el momento en que nosotros la moralizamos y nosotros formemos y controlemos a quienes sean los magistrados constitucionales; tranquilos, porque va a haber un control moral de constitucionalidad que va a anular toda reforma progresista tachándola inconstitucional por ir contra los valores sacrosantos, poco menos 
que contra el derecho natural. Ese es el sustrato histórico del neoconstitucionalismo actual, aunque muchos de los que hoy se dicen neoconstitucionalistas y lo son de buena fe no tengan idea de ese trasfondo y piensen que todo nace con Dworkin, quien tampoco sabía nada de esta historia, porque no era especialmente culto y venía de otra tradición y otro tipo de sistemas jurídicos.

No sé si va a regresar el positivismo jurídico y creo que tampoco importan mucho los nombres. Sería muy bueno que aparecieran no solo nuevas etiquetas con algún significado tangible, sino una teoría jurídica un poco más compleja, menos elemental. Lo que defiendo y creo que va a ocurrir es un retorno al valor de la legalidad ¿Qué quiero decir con valor de la legalidad? Que volverá el convencimiento de que la manera de proteger nuestros derechos es haciéndolos valer a través de leyes, a través de normas jurídicas positivas que los estipulen con la mayor claridad posible y que tengan autentica fuerza vinculante y autentica fuerza coactiva. Vuelvo al ejemplo de antes, si la Constitución o una ley dicen que a mí no se me tortura, no se me tortura, y no hay más que hablar ni que ponderar. Lo que propongo es la vuelta a la ley, en el sentido amplio de la expresión; es decir, que nos tomemos en serio lo que dicen la Constitución y las diversas leyes, aun sabiendo que hay indeterminación, que la discrecionalidad judicial no se puede eliminar y que siempre va a haber un componente valorativo en la práctica de Derecho. Pero hay que volver a tomarse el Derecho en serio para que se tomen los derechos en serio, porque en la tradición de la Jurisprudencia de Valores alemana, a la que antes me refería, y en la estela de Dworkin, los derechos no se toman en serio, no se respetan de verdad, sino según y cómo, caso a caso. Me gustaría que el pensamiento jurídico ilustrado retornara, me gustaría que volviera ese modo de pensar, llámese positivista o como se llame. Me gustaría que los profesores de Derecho de las universidades más caras de Latinoamérica dejaran de engañar al pueblo y que el pueblo volviera a tener derechos exentos de ponderaciones y cuentos. Para que, además, el pueblo 
aprenda de nuevo a luchar por sus derechos luchando por las leyes que los protejan, en lugar de echarse en manos de demagogos y de quienes les quieren convencer de que la revolución de los derechos la van a hacer los profesores más elitistas desde las universidades más caras y exclusivas.

AUB: Bueno, yo estoy encantada escuchándolo doctor, pero tengo que ir terminando con unas últimas preguntas. ¿Podría usted recomendarnos tres libros de Derecho que, desde su perspectiva, sean básicos para la formación de cualquier jurista?

JAGA: Hay que leer a los clásicos del siglo XX y hasta hoy. Me parece que sería muy bueno que todos leyeran lo que podríamos decir es la triada mágica de la teoría del derecho: Teoría pura del derecho. de Kelsen, El concepto de derecho, de Hart, y Sobre el derecho y la justicia, de Ross. A eso hay que añadir Teoría de la argumentación jurídica, de Robert Alexy. Aunque no estoy de acuerdo con Alexy en muchas cosas, reconozco que es un libro capital. Sumaría dos grandes obras de Ferrajoli, Derecho y razón y los dos primeros volúmenes de Principia iuris. Si alguien lee eso y lo medita, tiene una extraordinaria base en su formación de teoría y filosofía del Derecho. Si tuviera que seguir con más recomendaciones, mencionaría autores tan heterogéneos como Riccardo Guastini o Manuel Atienza.

AUB: Ahora, para finalizar, me gustaría saber esto: si alguien quisiera conocer a Juan Antonio García Amado ¿qué tendría que leer de sus obras?

JAGA: Si es que el esfuerzo valiera la pena, tendría que leer lo que más me gusta escribir, que son las obras más breves; por ejemplo, las cosas que sobre Derecho escribía antes en mi blog, Dura lex, y las que escribo ahora en un blog colectivo llamado Almacén de derecho. Me gusta mucho comentar sentencias y me gusta practicar un tipo de escritura que no es de libros, sino de artículos movidos por algún tipo de inspiración en un suceso reciente o hecho notable. Sinceramente, no creo que tenga gran valor lo que yo escribo, pero estoy orgulloso de dos cosas y voy a aprovechar tu amabilidad 
para resaltarlas. En primer lugar, orgulloso de entender la práctica de la Filosofía del Derecho como un debate; estoy muy feliz de lo que he publicado con Manuel Atienza, debatiendo entre nosotros. Saldrá en junio de 2020 una nueva polémica nuestra, esta vez sobre objetivismo moral y Derecho. Junto con mi amigo Manuel Atienza, me gusta mostrar a los colegas latinoamericanos que la Filosofía del Derecho solo progresa debatiendo y que debatir con alguien y contradecir sus tesis no es una forma de ofender, sino una manera de homenajear. Sólo se discute con quien vale la pena y con quien ha dicho algo interesante.

Por otro lado, hay una modestísima aportación de uno que también me da un poquito de orgullo y que consiste en tratar de escribir de Derecho con algo de sentido del humor. En general, y tanto en España como en Latinoamérica, el profesor de Derecho parece que se ha tragado una caja de palillos y que no consigue expulsarlos, la gente teoriza con dolor y mala sangre y da la impresión de que uno no está escribiendo sobre Teoría del Derecho o Derecho constitucional, supongamos, sino que está redactando una carta a sus deudores para que acaben de pagarle algo que le deben. Creo que tenemos que relajarnos un poco y tratar de escribir bien. Por qué no considerar que también hay algo de literario en lo que hacemos y que conviene igualmente ponerle humor y un toque lúdico a nuestro oficio.

AUB: Le agradezco muchísimo, doctor Juan Antonio García Amado, por la entrevista. Estoy fascinada al escucharlo y me encantaría volver a hacerlo pronto. Sinceramente nos sentimos muy orgullosos de conocerlo y esperamos que nos visite cuando le sea posible. En particular de parte de la Revista del Posgrado en Derecho, le transmito nuestro profundo agradecimiento por haber aceptado nuestra entrevista y deseamos poder conversar con usted nuevamente.

JAGA: Muchas gracias, espero que pronto tengamos ocasión para seguir colaborando y charlando de tantas cosas. 